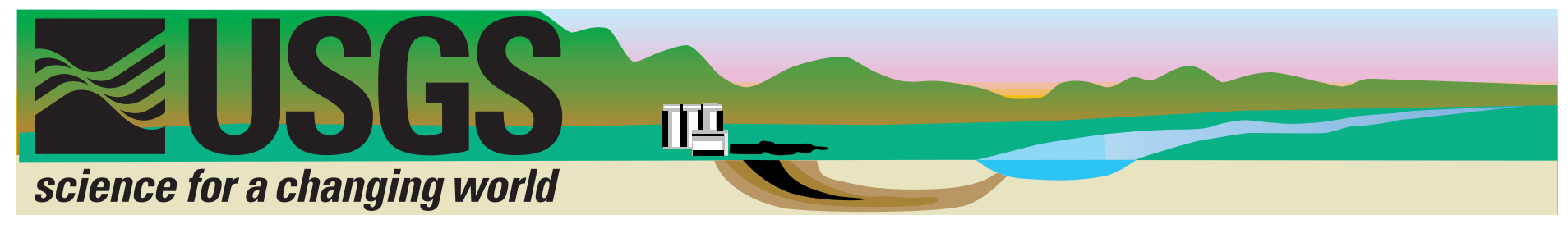

\title{
SIMULATING TRANSPORT OF VOLATILE ORGANIC COMPOUNDS IN THE UNSATURATED ZONE USING THE COMPUTER MODEL R-UNSAT
}

Subsurface spills of gasoline and other petroleum products are a common environmental problem throughout the industrialized world. The U.S. Environmental Protection Agency has estimated that 40 percent of the more than 200,000 retail service stations in the United States have had accidental releases of petroleum hydrocarbons to the subsurface (U.S. Environmental Protection Agency, 1991). Restoration of a contaminated aquifer to regulatory standards is a technically difficult problem even when best engineering strategies are applied.

Natural attenuation, a remediation strategy that relies on intrinsic physical, chemical, and biological processes to decrease contaminant concentrations, is gaining widespread acceptance in aquifer restoration efforts (Tremblay and others, 1995). The potential for successful remediation by natural attenuation depends on the fate of the organic constituents of the spilled product, which may include additives such as methyl tert-butyl ether (MTBE). These compounds can dissolve in ground water, adsorb to subsurface sediments, volatilize and diffuse through the unsaturated zone, or undergo chemical and biological reactions (fig. 1). Volatilization and biodegradation near the water table are two processes that can contribute significantly to the natural attenuation of volatile organic compounds (VOCs) in shallow ground water (McAllister and Chiang, 1994). To date, quantitative information on the rates at which these processes occur has been limited.

R-UNSAT, a computer model designed for quantifying rates of volatilization and biodegradation of organic compounds near the water table, was developed and documented by the U.S. Geological Survey (USGS) and is now available to the public. R-UNSAT also can be applied, however, to other unsaturated-zone transport problems that involve gas diffusion, such as radon migration, and the deposition of compounds from the atmosphere to shallow ground water. This fact sheet describes the transport model and demonstrates its capabilities through applications to point- and nonpoint-source contamination.

\section{MODEL DESCRIPTION}

\section{CAPABILITIES AND LIMITATIONS}

R-UNSAT is designed to simulate reactive, multispecies transport in a layered unsaturated zone with variable moisture content (fig. 2). Two-dimensional (axisymmetric) model equations are solved by using a finite-difference algorithm. Analytical solutions for simulating one-dimensional, vertical transport of a nonreactive species in a homogeneous unsaturated zone also are provided. Gas transport is based on Fick's Law of diffusion; therefore, application of R-UNSAT is inappropriate if gasphase advection is significant (for example, in soil-vapor extraction applications). R-UNSAT can be applied, however, to simulate advective transport of compounds in the aqueous phase associated with ground-water recharge. R-UNSAT accounts for equilibrium partitioning of mass among immiscible (the petroleum-product source), solid, aqueous, and gaseous phases. The immiscible phase is assumed to be stationary and is modeled as a

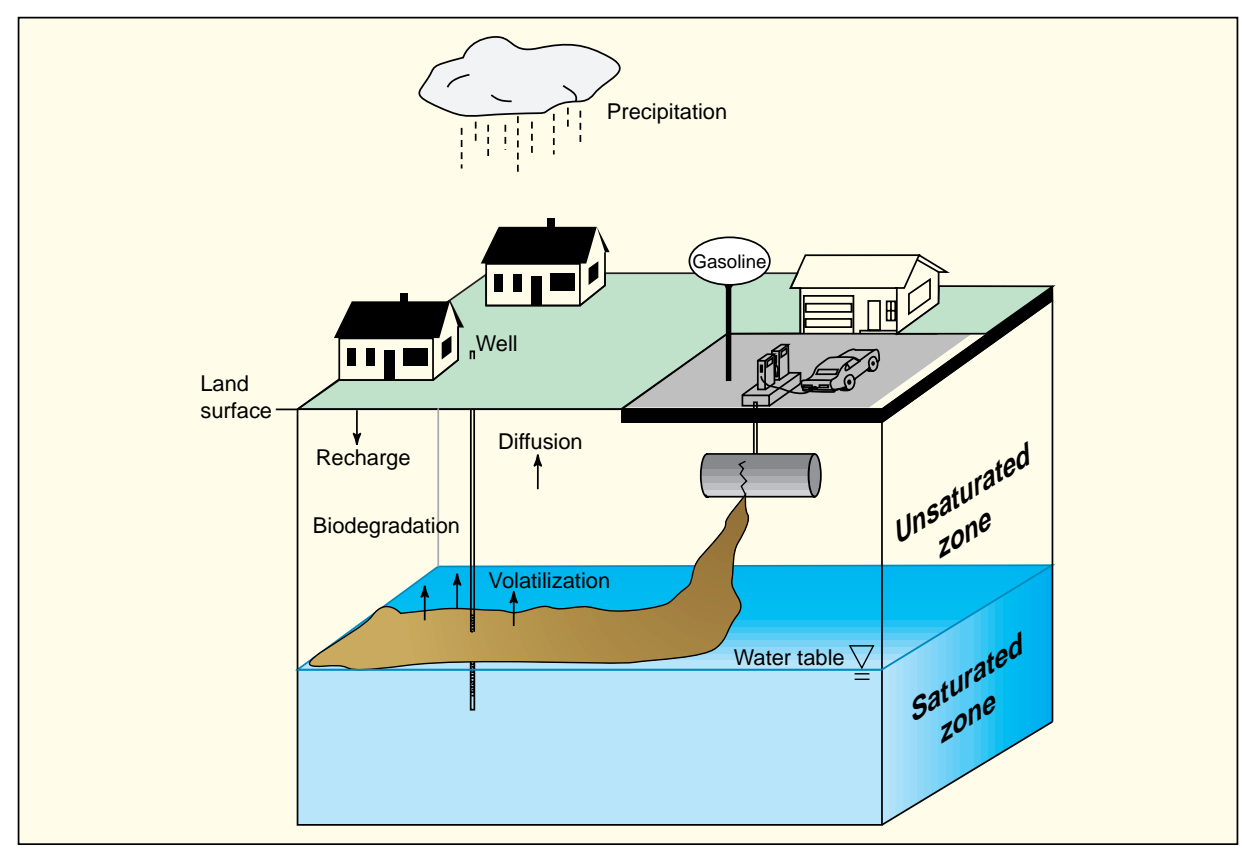

Figure 1. Conceptualization of the fate of petroleum hydrocarbons in a groundwater system. 
boundary condition.

Biogeochemical reactions can be sources or sinks for each modeled species. The user can select either a zeroor first-order kinetics model for these purposes. A single species can be ratelimiting or the reaction kinetics can be coupled; for example, the production rate of one species can be defined by the consumption rate of another. If the available kinetics models are not appropriate, the user can substitute his or her own model directly into the computer program. The modular format of the Fortran 77 code easily accommodates this type of modification.

\section{BOUNDARY AND INITIAL CONDITIONS}

The availability of alternative boundary and initial conditions provides the flexibility to apply R-UNSAT to a wide variety of transport problems. For example, one of the following boundary conditions can be selected to characterize the source (fig. 3):

Option 1: Specified-flux boundary (upper- or lower-vertical boundary)

Option 2: Specified-concentration boundary (upper- or lowervertical boundary)

'Option 3: Time-dependent-concentration boundary

'Option 4: Constant-radial-flux boundary

${ }^{1}$ Available only with numerical solver

Options 1 and 2 are designed for modeling a source at land surface or at the water table. The source strength remains constant over the duration of the simulated event, and the transport of one species does not affect transport of another. These options were applied by Lahvis and Baehr (1996) to estimate rates of aerobic hydrocarbon biodegradation in a shallow ground-water plume. Option 3 is appropriate for multispecies transport modeling if the product source is at or above the water table. In this option, the source composition varies as a function of time in accordance with constituentmass fluxes across source boundaries. Baehr (1987) applied this boundary condition to simulate the long-term compositional evolution of a gasoline-

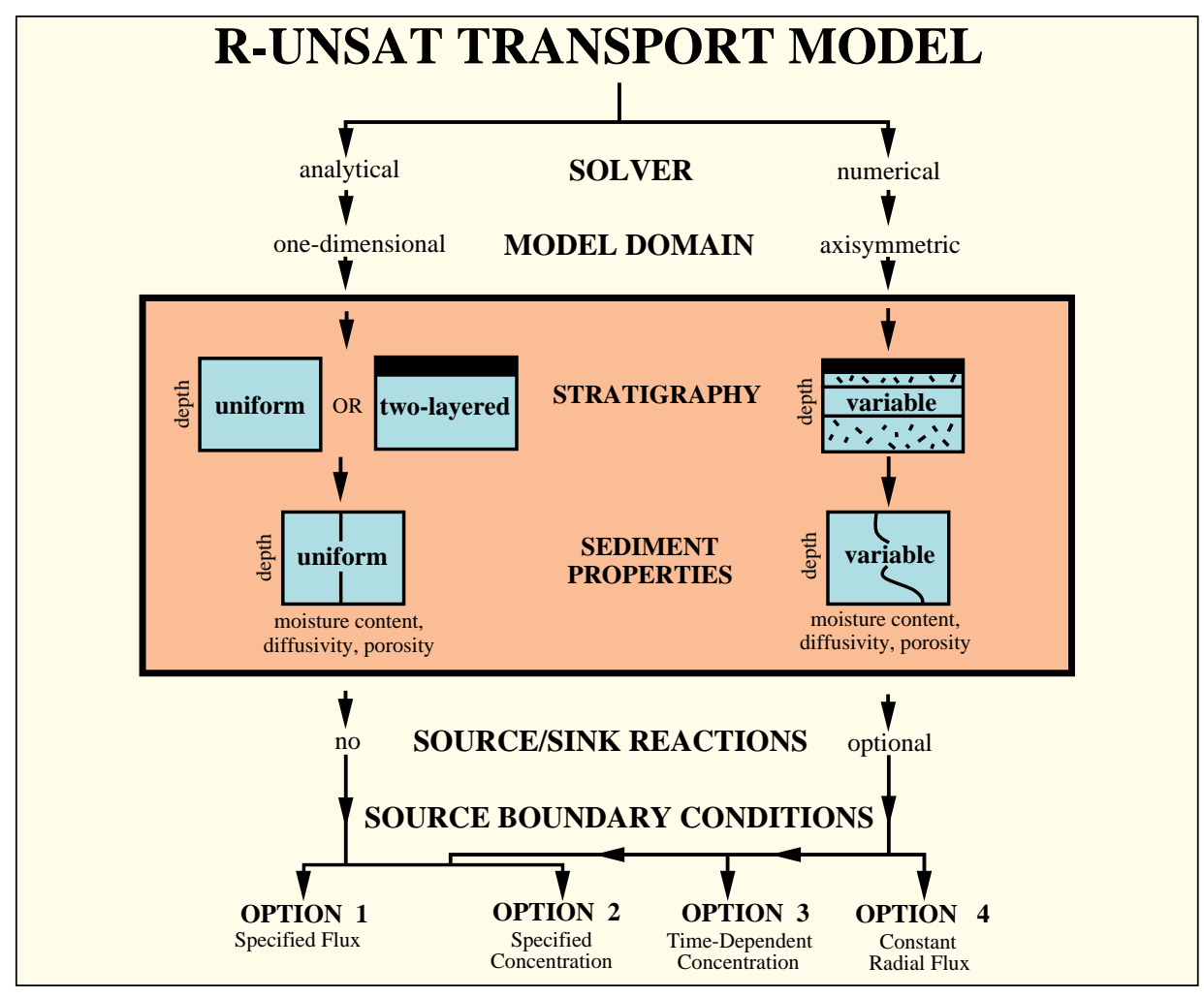

Figure 2. Flow diagram of R-UNSAT transport model.

spill source. Option 4 is designed to simulate a constant-source flux in the unsaturated zone--for example, a tracer experiment to estimate effective-diffusive coefficients of unsaturated-zone sediments.

The remaining (upper- and/or lower-vertical and far-lateral) boundaries are modeled as variable-flux boundaries that can be mixed for more complex applications. For example, one part of the boundary can be modeled as a semipervious condition and another part can be modeled as an impervious condition.

The initial condition of each species can be specified as a constant concentration throughout the model domain or defined spatially with an input file. The latter option is useful for evaluating transport after the contaminant source has been removed or when incorporating data from a soil-gas survey. An example of selected model input to RUNSAT is shown in table 1 .

\section{MODEL APPLICATIONS}

R-UNSAT can be used for calibration or prediction purposes. In a calibration mode, R-UNSAT can be used to quantify rates of mass transport, reaction rates, or the transport properties of unsaturated-zone sediments. Parameter values are computed by calibration to gas or aqueous concentrations measured in the unsaturated zone. R-UNSAT also can be used to predict the distribution of a species as a function of time and space and to estimate mass-loss or loading rates across model boundaries. Examples of both types of applications are presented below.

\section{APPLICATIONS TO ANALYSIS OF POINT-SOURCE CONTAMINATION}

\section{Predicting the Evolution of a Gasoline- Spill Source}

Large volumes of gasoline can remain trapped in the unsaturated and capillary zones of an aquifer after primary remediation efforts have ceased. Because gasoline is composed of constituents with diverse phasepartitioning properties, the source concentration of each constituent varies over time as constituents are selectively removed from the residual product. Baehr (1987) applied a preliminary version of R-UNSAT in a predictive mode to demonstrate that release rates for aromatic constituents such as benzene, 


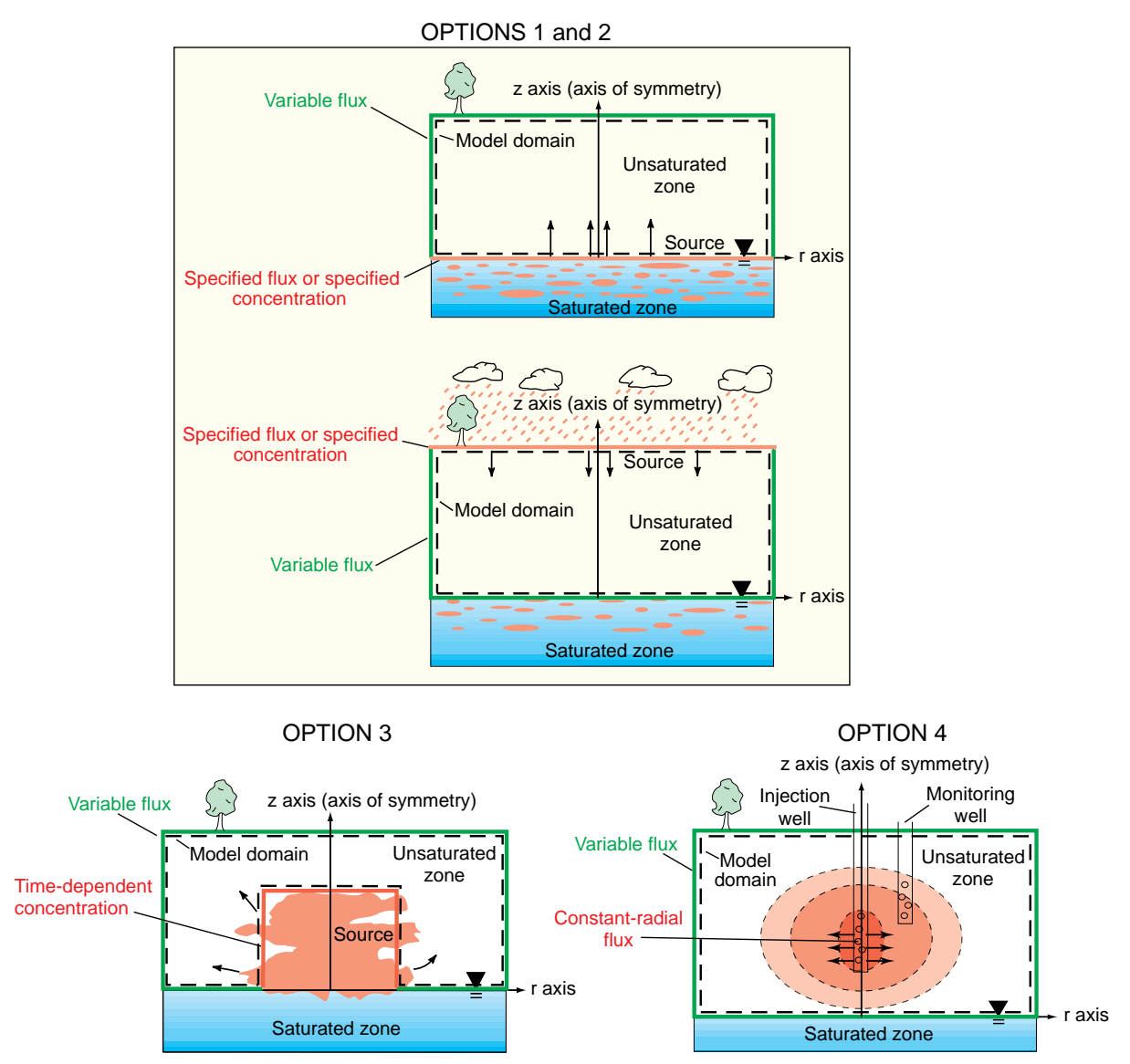

Figure 3. Model geometry and boundary conditions available in R-UNSAT.

toluene, ethylbenzene, and xylenes (BTEX) are greatest at some time after the spill incident. This lag in the peak release rate is caused by the increasing enrichment of the aromatic fraction of the residual phase as more volatile aliphatic compounds are selectively removed by volatilization.

\section{Estimating Rates of Aerobic Biodegradation of Hydrocarbons Associated with Bioventing}

Aerobic biodegradation of hydrocarbons in the subsurface by indigenous microorganisms results in the depletion of oxygen $\left(\mathrm{O}_{2}\right)$ and the production of carbon dioxide $\left(\mathrm{CO}_{2}\right)$. Aerobic biodegradation can be inhibited or even halted if the availability of $\mathrm{O}_{2}$ is limited. In these cases, bioventing can be used as a remediation technique to maintain or enhance the $\mathrm{O}_{2}$ supply by delivery of atmospheric $\mathrm{O}_{2}$ to the contaminated region through vapor extraction. Consequently, near-atmospheric concentrations of $\mathrm{O}_{2}$ can be achieved throughout the unsaturated zone, even immediately above the water table. If vapor extraction a challenge to remediation by natural attenuation because the concept was developed in the context of BTEX compounds.

R-UNSAT is currently (1998) being applied to quantify the rates of mass transfer of MTBE and BTEX from ground water to the unsaturated zone due to volatilization and diffusive transport at a gasoline-spill site in South Carolina. Calibration of R-UNSAT to unsaturatedzone gas-concentration data indicates that the volatilization rate of MTBE from the water table source to the unsaturated zone is similar to the volatilization rate of BTEX. This finding is critical to the evaluation of natural-attenuation remediation, because rates of natural attenuation in the interior of a groundwater-solute plume are smaller for MTBE than for BTEX.

Table 1. Selected model input to R-UNSAT transport model

\section{SELECTED MODEL INPUT}

Constituent Properties

Number of modeled constituents

Molecular weight

Atomic diffusion volume

Gaseous-phase diffusivity

Aqueous-phase diffusivity

Specific volume

Henry's Law constant

Aqueous-phase solubility

Adsorption isotherm

$\mathrm{gal} / \mathrm{ft}^{2} / \mathrm{yr}$ associated with bioventing at a gasoline-spill site in Galloway Township, New Jersey.

\section{Estimating Rates of MTBE and Hydrocarbon Mass Transfer to the Unsaturated Zone}

MTBE is added to gasoline in some parts of the country to reduce carbon monoxide and ozone emissions to the atmosphere. Gasoline oxygenated with MTBE can contain as much as 14.8 percent MTBE by volume. MTBE is more soluble and less degradable than BTEX compounds and, therefore, has been observed to migrate ahead of BTEX compounds in ground water at gasolinespill sites (Landmeyer and others, 1996). Spills of MTBE-oxygenated gasoline are
Boundary and Initial Conditions

Gas flux across source boundary (Option 1) Gaseous-phase concentration at source boundary (Option 2)

Initial mole fraction in immiscible plume (Option 3)

Immiscible plume volumetric content (Option 3)

Radius of source

Gaseous-phase concentration at other model boundaries

Physical Properties of the Unsaturated Zone

Total porosity

Aqueous-phase porosity

Gaseous-phase tortuosity

Bulk density

Unsaturated-zone temperature

Unsaturated-zone pressure

Number of sediment layers

Vertical recharge rate

Longitudinal and transverse dispersivities 
APPLICATION TO ANALYSIS OF

NONPOINT-SOURCE

CONTAMINATION--ATMOSPHERIC DEPOSITION

Advances in analytical chemistry and sampling techniques have resulted in the ability to quantify concentrations of VOC in ground water of 0.1 micrograms per liter or less. VOC's have been detected frequently at these low concentrations in samples of shallow ground water collected across the country as part of the USGS National Water Quality Assessment (NAWQA) program (Squillace and others, 1995). An understanding of the source of VOC's detected in ground water is critical in areas where surficial aquifers are used for water supply. If atmospheric deposition is the source of a VOC in ground water, then changes in VOC concentration over time would be constrained and proportional to changes in atmospheric concentration. If, however, the VOC presence is due to coalescing point sources, then concentrations could increase significantly, posing a more serious threat to the water supply. The USGS has initiated a research project in southern New Jersey to investigate the role of atmospheric deposition in shallow-ground-water contamination by applying R-UNSAT to compute rates of VOC migration in the unsaturated zone.

\section{MODEL COMPATIBILITY AND AVAILABILITY}

The R-UNSAT computer code is written in Fortran 77 and runs on a variety of computer platforms, including mainframes and personal computers. RUNSAT is written in a modular structure that facilitates modifications to the source code. If modifications are made, the program must be recompiled with a Fortran 77 compiler to incorporate the changes into the executable version of the computer code. The compiling procedure varies depending on the computing system and the Fortran 77 software. Documentation of R-UNSAT is available as a U.S. Geological Survey Open-File Report (Lahvis and Baehr, 1997). The documentation, along with the source code and executable versions, also can be accessed on the Internet at the following

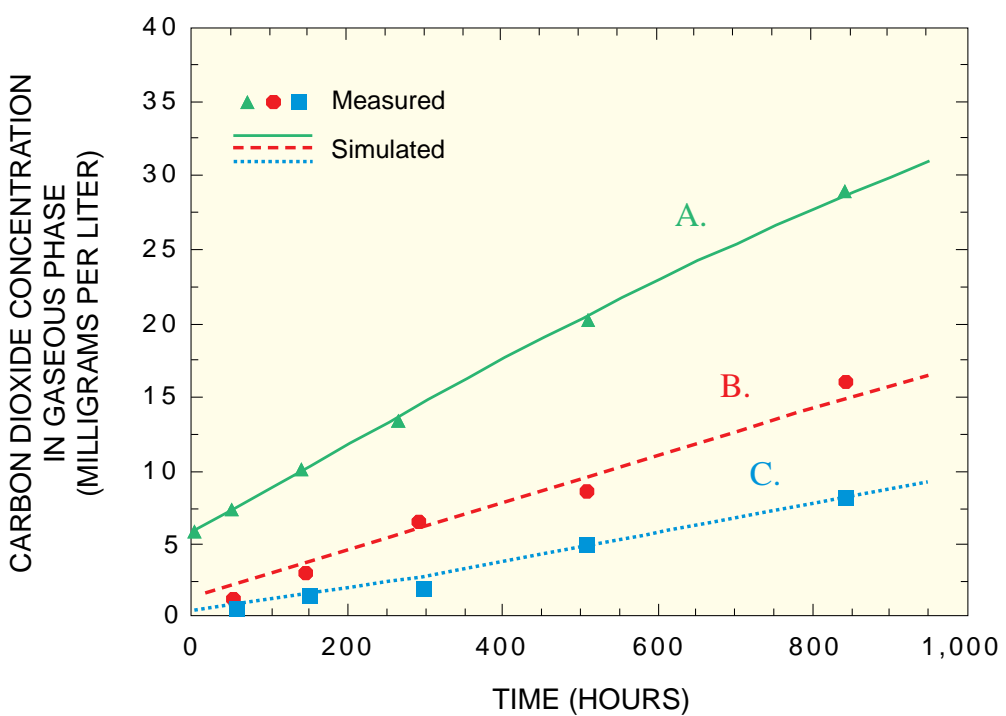

Figure 4. Graph showing model calibration to rebound of carbon of carbon dioxide concentrations at (A) 8.2 feet, (B) 7.4 feet, and (C) 6.0 feet below land surface.

website address:

http://wwwnj.er.usgs.gov/

Additional information on the fate and transport of VOC's in the subsurface can be obtained at the U.S. Geological Survey Toxic Substances Hydrology Program website at

http://toxics.usgs.gov/toxics.

--- Matthew A. Lahvis and Arthur L. Baehr

\section{REFERENCES CITED}

Baehr, A.L., 1987, Selective transport of hydrocarbons in the unsaturated zone due to aqueous and vapor phase partitioning: Water Resources Research, v. 23, p. 19261938.

Lahvis, M.A., and Baehr, A.L., 1996, Estimation of rates of aerobic hydrocarbon biodegradation by simulation of gas transport in the unsaturated zone: Water Resources Research, v. 32, p. 2231-2249.

1997, Documentation of R-UNSAT, a computer model for the simulation of reactive, multispecies transport in the unsaturated zone: U.S. Geological Survey Open-File Report 97-630, 104 p.
Landmeyer, J.E., Chapelle, F.H., and Bradley, P.M., 1996, Assessment of intrinsic bioremediation of gasoline contamination in the shallow aquifer, Laurel Bay Exchange, Marine Corps Air Station, Beaufort, South Carolina: U.S. Geological Survey Water-Resources Investigations Report 96-4026, $50 \mathrm{p}$.

McAllister, P.M., and Chiang, C.Y., 1994, A practical approach to evaluating natural attenuation of contaminants in ground water: Ground Water Monitoring Review, v. 14, p. 161173.

Squillace, P.J., Zogorski, J.S., Wilber, W.G., and Price, C.V., 1995, A preliminary assessment of the occurrence and possible sources of MTBE in ground water of the United States, 1993-94: U.S. Geological Survey Open-File Report 95-456, $15 \mathrm{p}$.

Tremblay, D., Tulis, D., Kostecki, P., and Ewald, K., 1995, Innovation skyrockets at 50,000 LUST sites: Soil and Groundwater Cleanup, December 1995, p. 6-13.

U.S. Environmental Protection Agency, 1991, OUST corrective action 45day study team report: U.S. Environmental Protection Agency, Office of Underground Storage Tanks, Washington, D.C. 